\title{
خصائص العلم العربي عند رشدي راشد
}

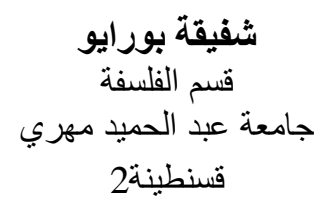

بـأثدة العلوم البحتـة و التطبقيبة عند

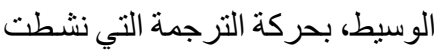
في أو اخر القرن 1 هـ المو افق للقرن

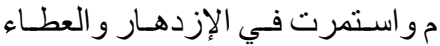

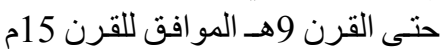

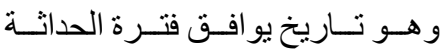

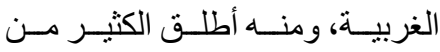

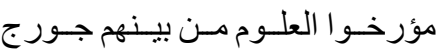

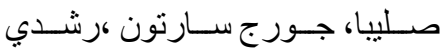

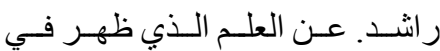

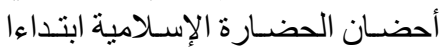
من القرن 2هـ المو افق للقرن 8م.

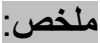

يقدم رشدي راثد من خلال أعماله كمؤرخ علوم يهتم

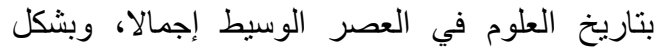
خاص العلوم العربية. موقفه الر افض لمقولة "الإنتماء العاء

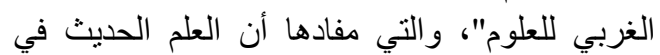
أساسه أوروبي متجدر في العلم ولتي والفي الفلسفة اليونانية. محاو لا فهم الفجوة الموجودة بين العلم اليوناني و العلم العماني

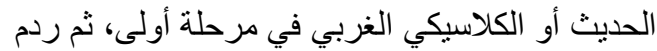

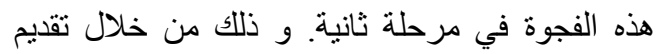

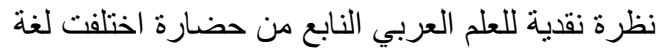
و ثنقافة، وأصول ممثليها من العلماء عدا إنتشر اكهم في نقطة أساسية و وحيدة هي اللغة العربية كلغة علم .

\section{Résumé:}

Par ses travaux Roshdi Rashed s'en prend au postulat grec, c'est -à-dire à l'idée que la science moderne est fondamentalement européenne et Qu'elle est essentiellement dérivée de la science et de la philosophie grecque.

L'historien des sciences, On ne cessant de porter un regard critique sur le domaine de son activité, défini précisément la place des sciences arabes entre Antiquité et Age classique, on marquant les différentes composants de cette science, issue d'une civilisation dont les représentants peuvent être de langues et de cultures différentes et qui adoptent l'arabe comme langue scientifique. 
تسمية العلم العربي لأن تسمية إسلامي قد تطرح إشكالية في جوهر العلوم الدنيوية بشكل خاص بما

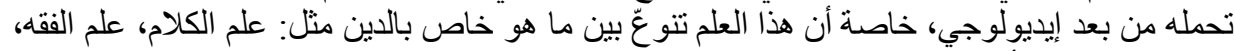

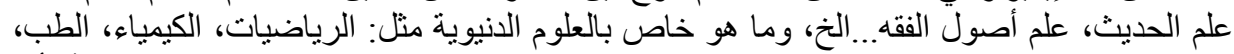

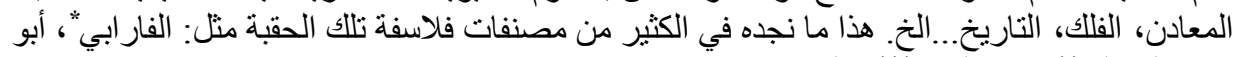

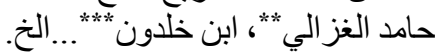

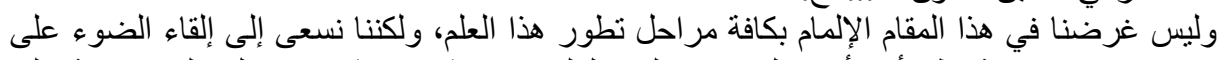

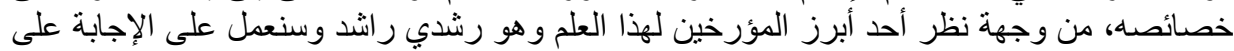

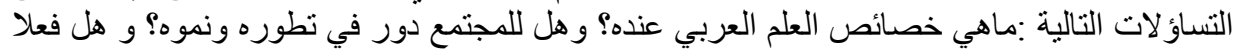

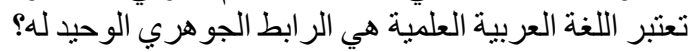
العلم العربي

يحصر مؤرخ العلوم رشدي ر اشدث****، العلم العربي في كل ما كتب بالعربية عندما كانت المر اكز العلمية

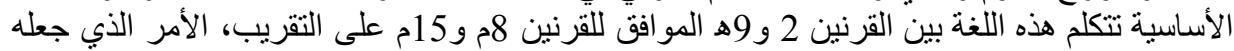

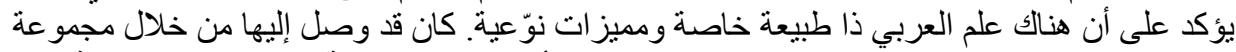

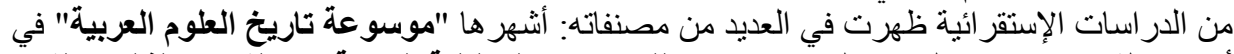

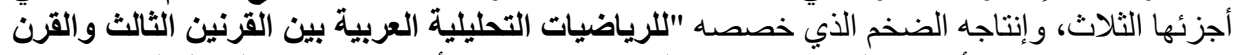

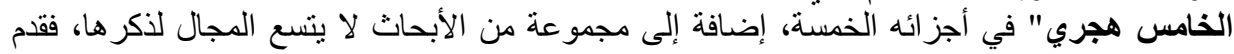

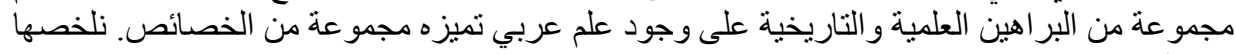

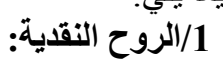

منذ بداية الحركة العلمية، بدأ العلماء العرب في جمع كل ما يمكن أن يقع تحت نظر هم من وثائق علمية

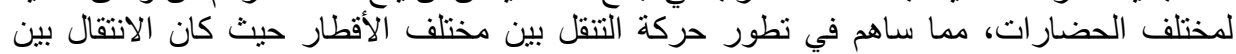

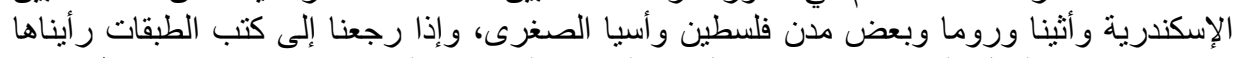

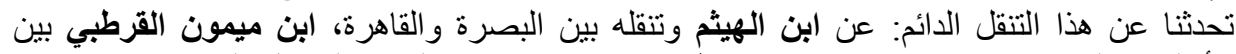

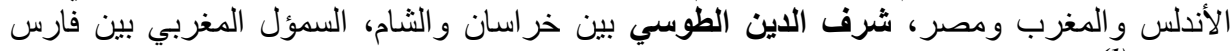
وسمرقند (1)

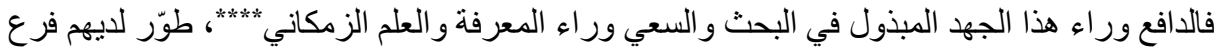

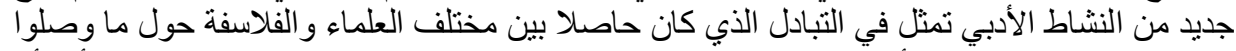

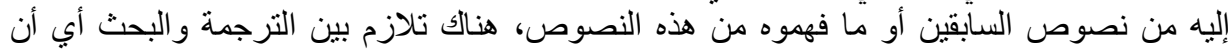

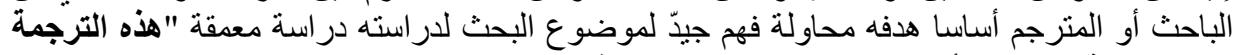

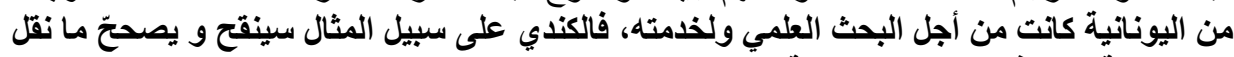

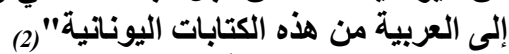

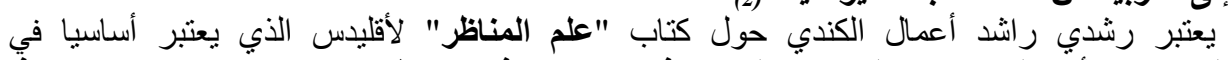

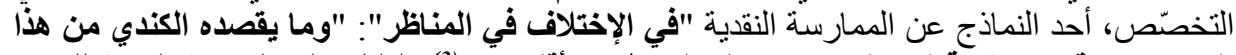

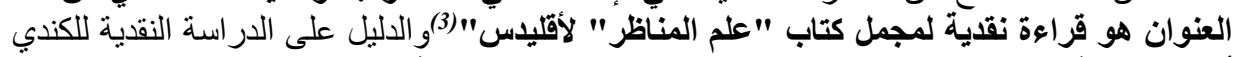

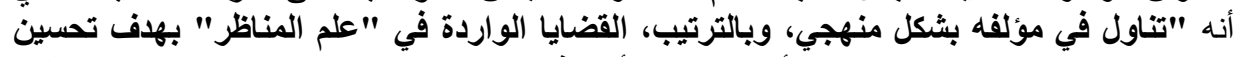

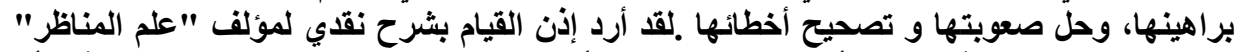

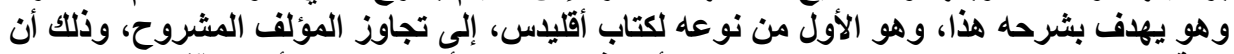

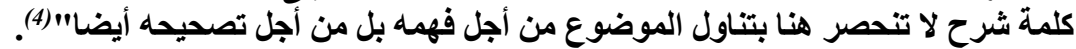

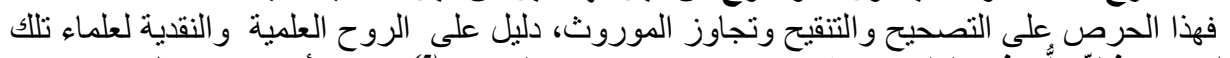

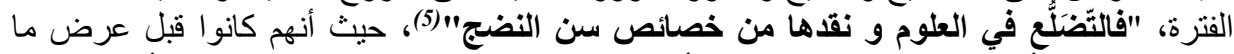

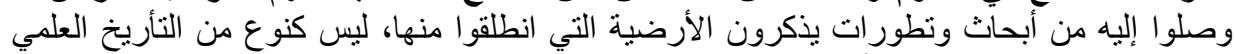

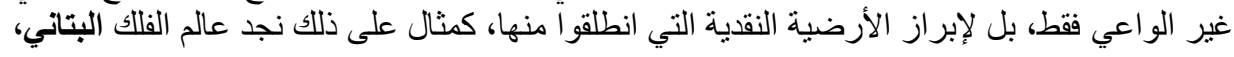




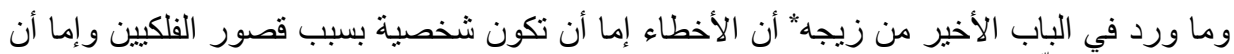

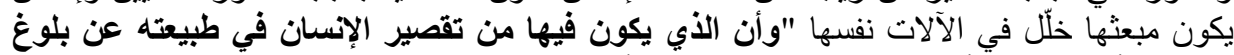

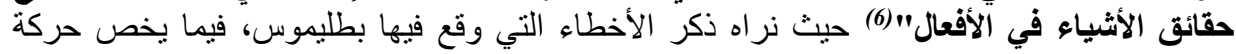

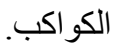

و هذا أبي الريحان البيروني يقدم مؤلفا نقديا في الفكر الهندي "تحقيق ماللهند من مقولة مقبولة في

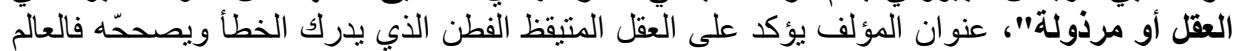

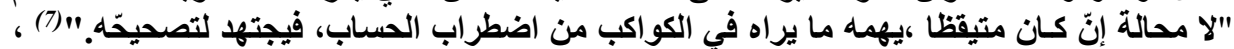

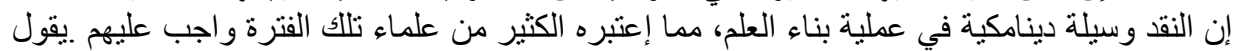

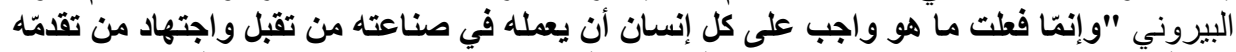

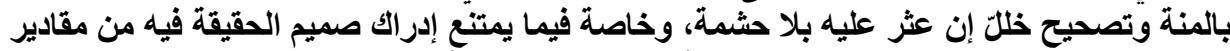

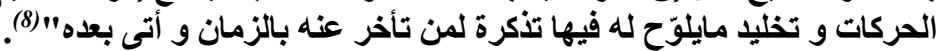

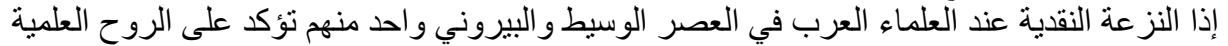

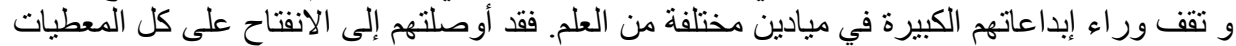

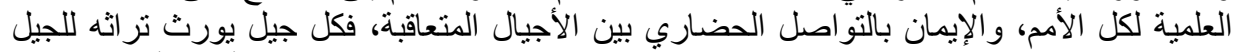

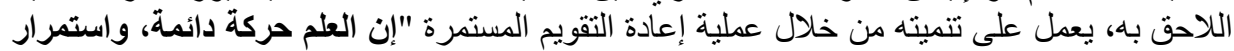

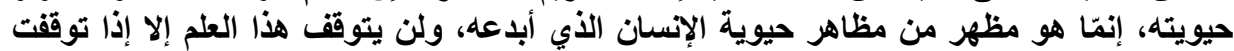

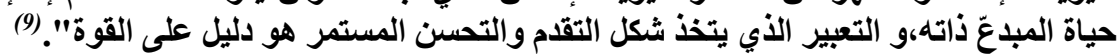

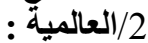

تحدّث رشدي راثد عن عالمية العلم العربي، بشكل كلي، ولكن لكي نتمكن من فهمها وتوضيحها قمنا

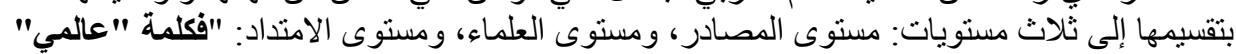

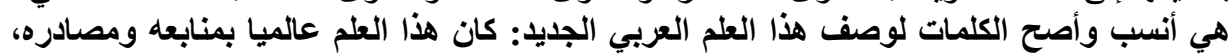

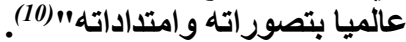
أ أمستوى المصادر:

لقد ظهر وتطور العلم العربي وفق ثلاث مر احل: مرحلة الترجمة والاقتباس، مرحلة البحث والتأليف،

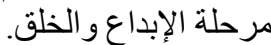

وقد ظهرت خاصية عالمية العلم العربي منذ المرحلة الأولى، حيث تميزت الحضارة العربية الإسلامية

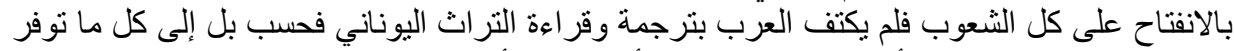

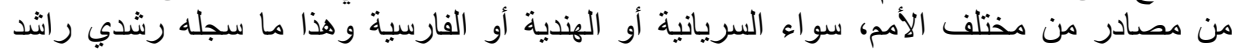

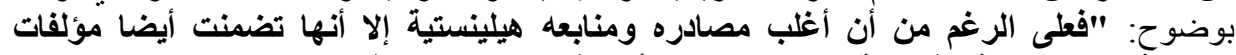

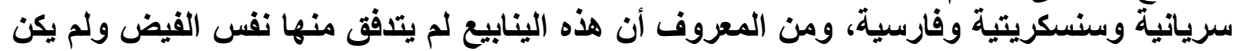

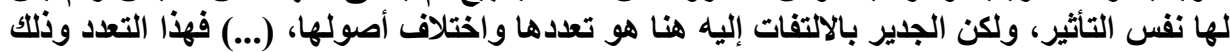

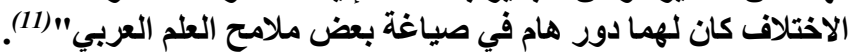

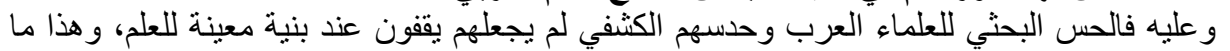

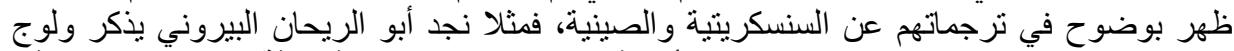

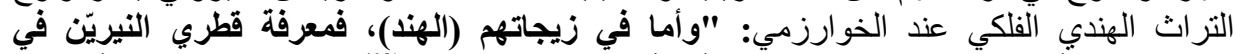

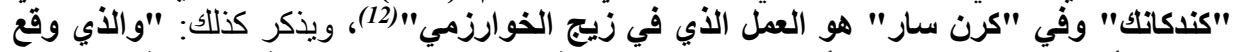

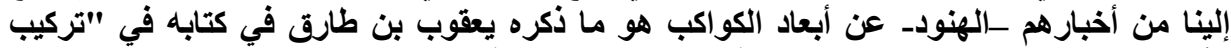

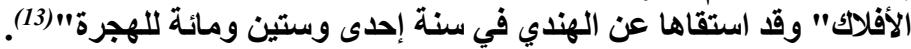

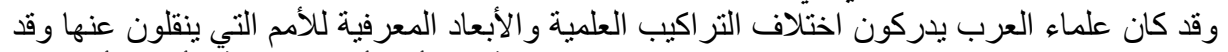

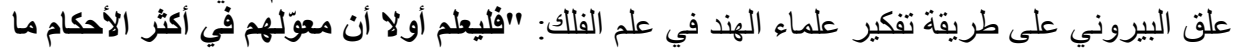

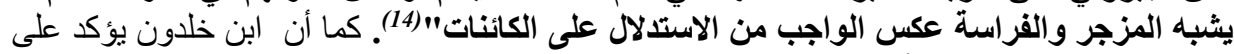

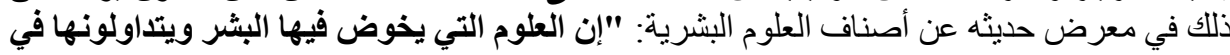




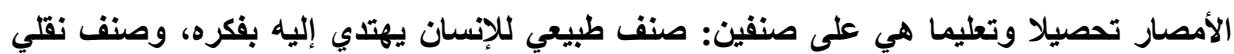

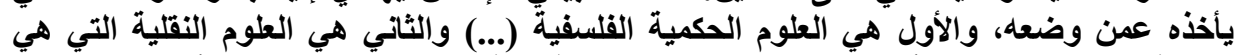

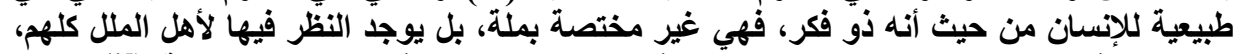

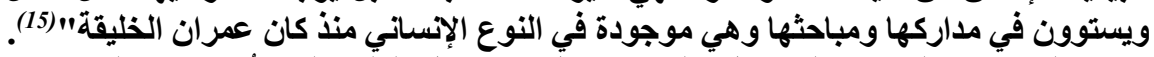

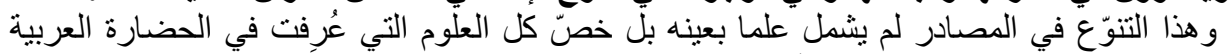

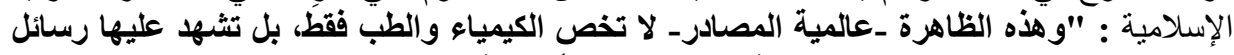

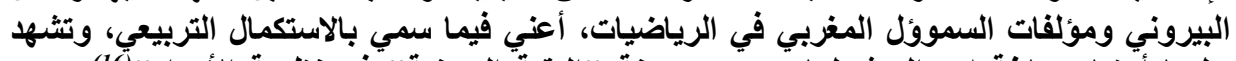

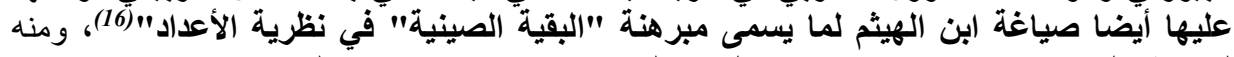

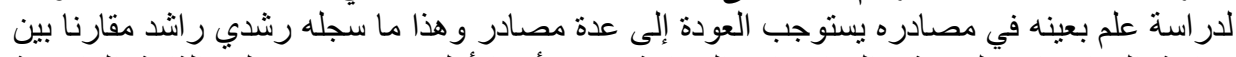

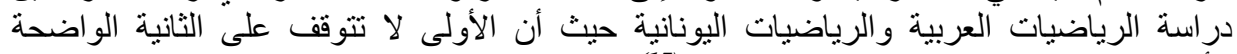
الأصول بل ضرورة العودة إلى إلى مصادر مختلفة (17). ب/مستوى العلماء:

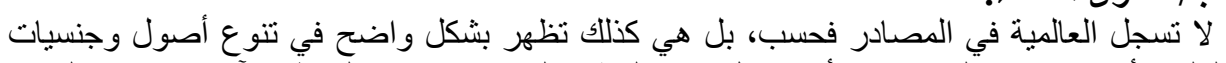

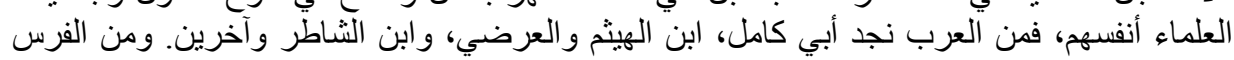

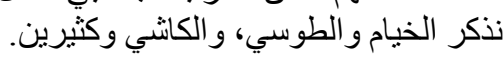

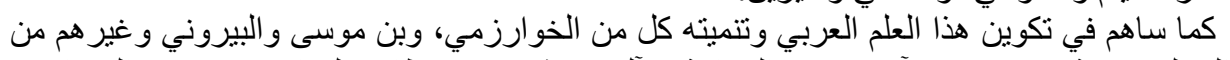

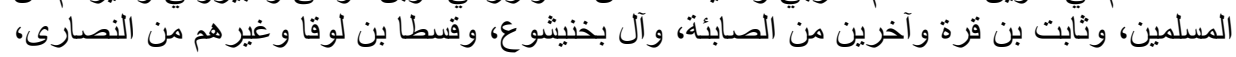

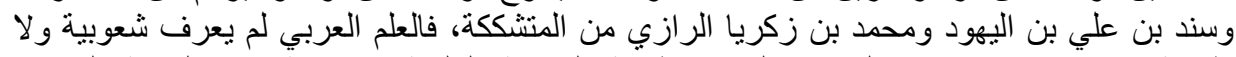

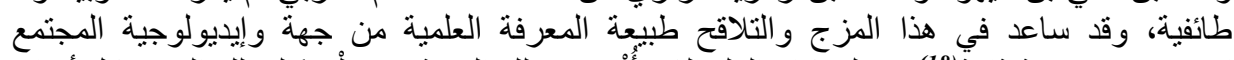

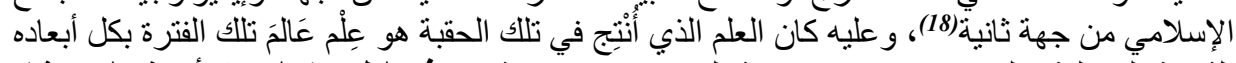

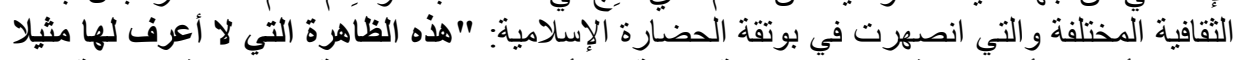

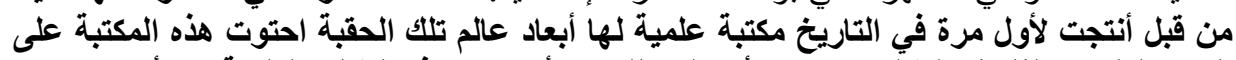

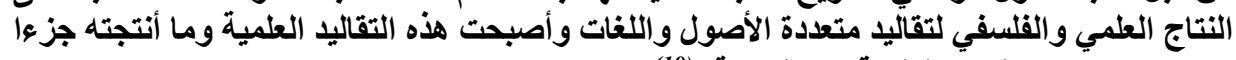

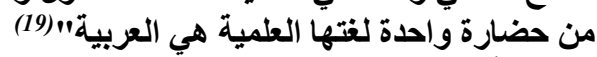

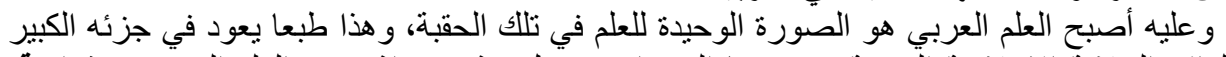

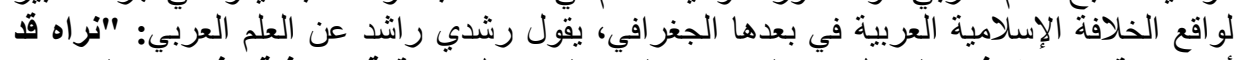

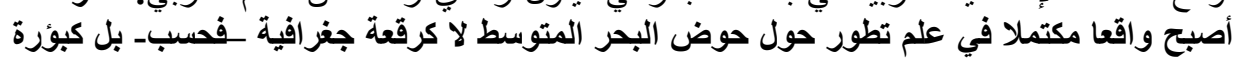

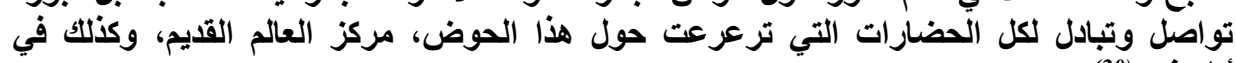

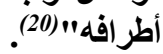

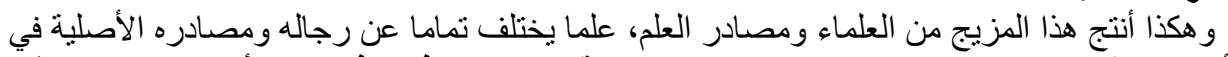

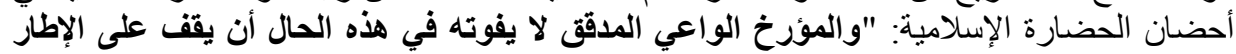

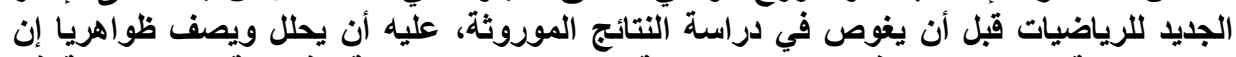

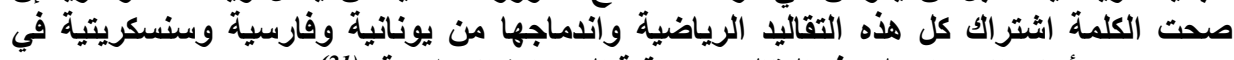
مجتمع جديد أعني انصهار كل هذه التقاليد تحت قبة التبة الحضارة الإسلامية" (21).

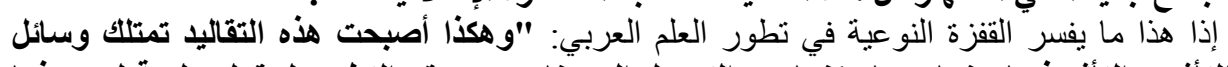

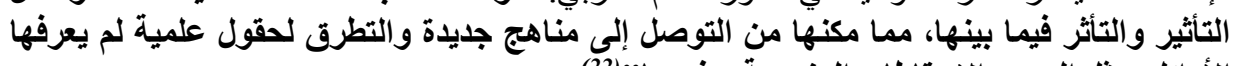

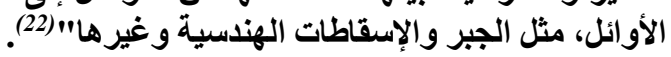

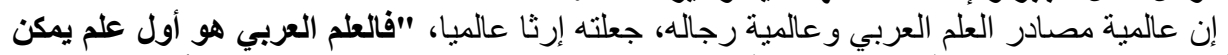

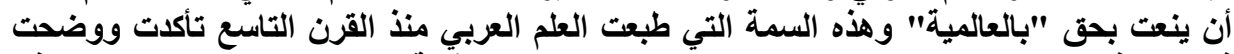

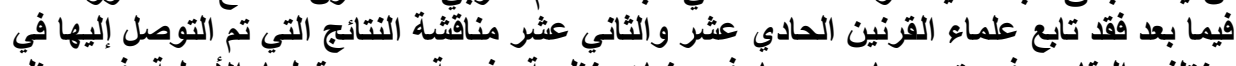

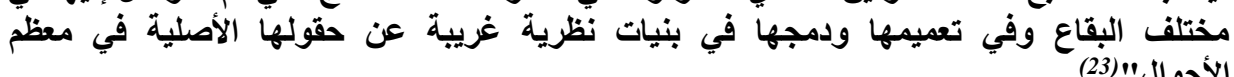


ج/مستوى الامتداد:

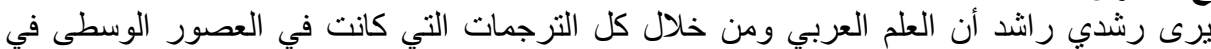
أوروبا والتي تم من خلالها ترجمة التراث العلمي العربي اليكي اليكون هو نقطة البداية في الحداثة الكلاسيكية فهو إرث عالمي بمعنيين: أو لا: الترجمة إلى اللاتينية والعبرية في أوربا، حيث أصبح هو المصدر الأساسي للتعليم، ففي مجال

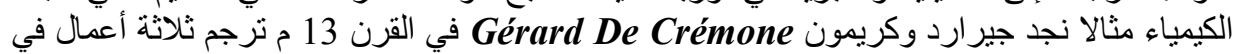
الكمباء:

Liber dicrmitatis de LXX ل

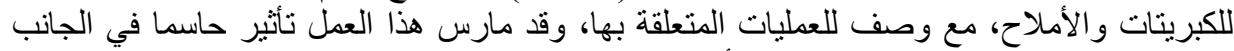

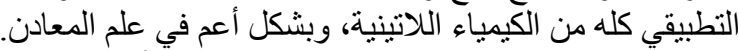
السحر (24). وقد أصبح اللاتينيون، ومنذ القرن 13م، مطلعين وبشكل كاف على المعرفة الجديدة، لكي يقدمو أعمال

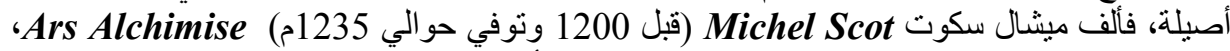
حيث يتحدث فيه عن تطبيث انتشر في العالم الإسلامي أو في العالم المسيحي، وارتكز على تجارة العطارين. وقد بيّن شيار الكريسياني Chiara Crisciani

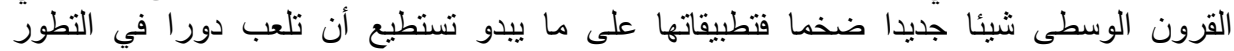

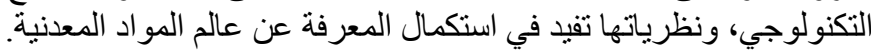

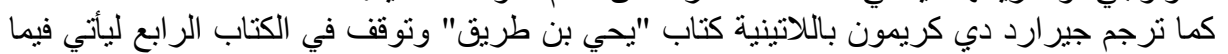

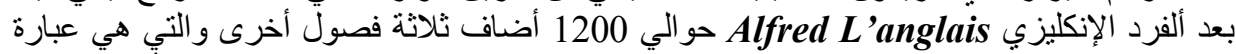

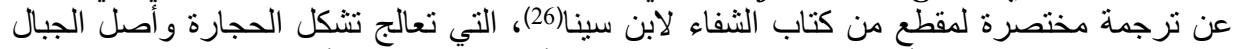

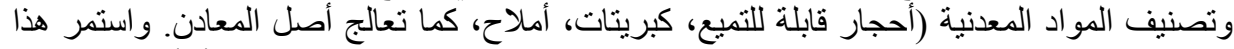

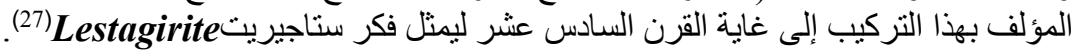

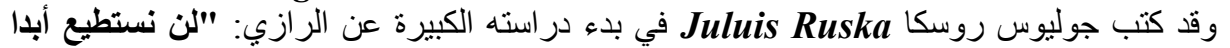

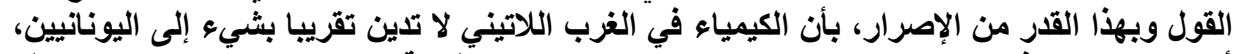

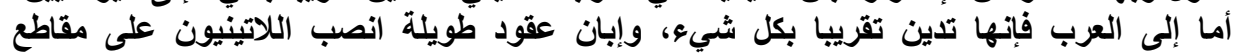

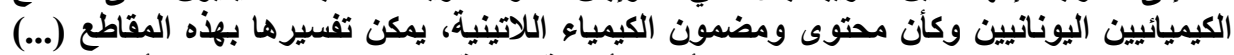

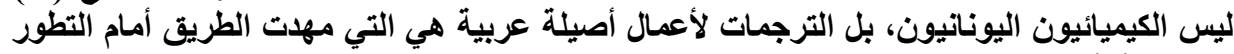
الغربي" (28). (الغيون أما في مجي "الال علم الفلك، فيسجل أول دليل على دخول علم الفلك العربي إلى الغرب اللاتيني

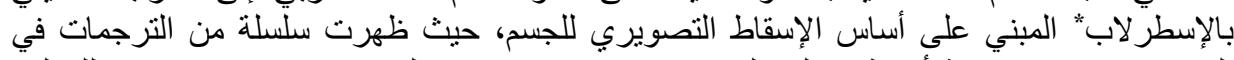

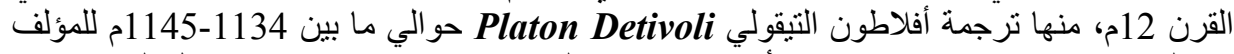

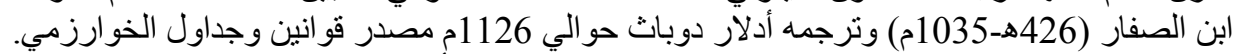

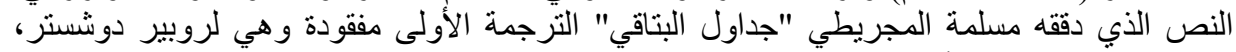

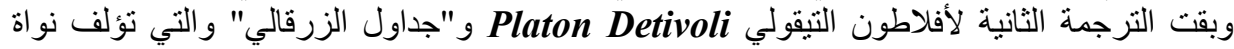

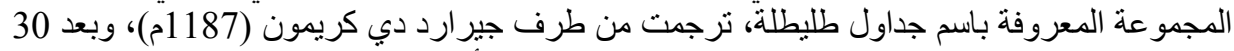

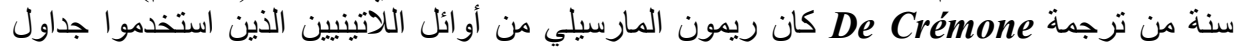

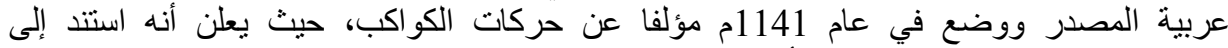
"الزرقالي"، كما استخلص منه فكرة أن الجداول الفلكية تتطلب تصحيحات مستمرة 
وقد استمرت حركة اقتباس الجداول العربية، وبشكل أساسي جداول طليطلة****** في أنحاء العالم

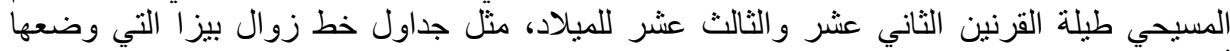

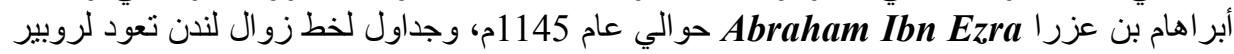

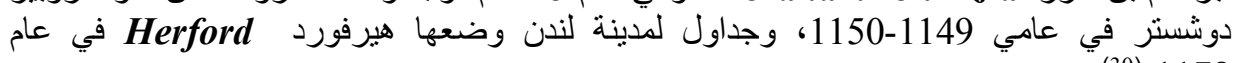
(30) 1178 118

إذن السمات المميزة للجداول اللاتينية من القرنين الثاني عشر والثالث عشر هي نفسها سمات جداول

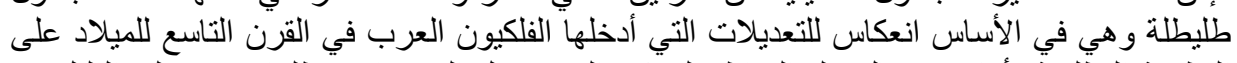

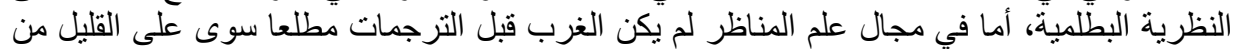

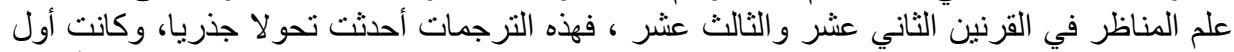

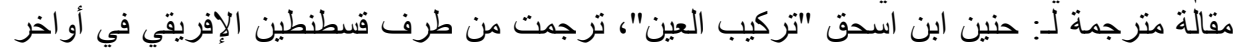

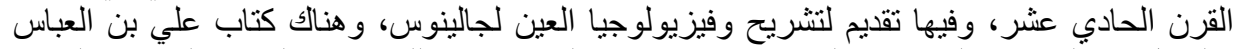

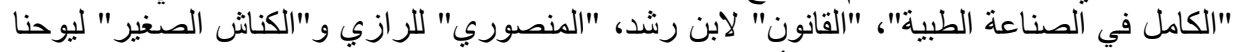

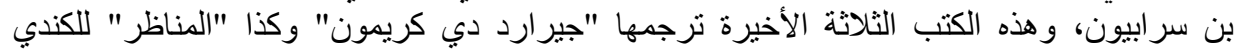

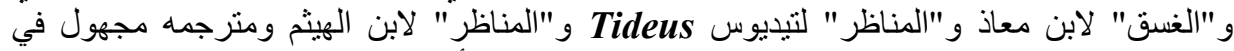

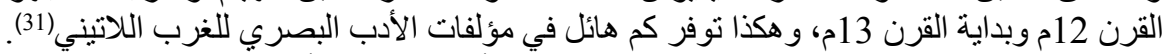

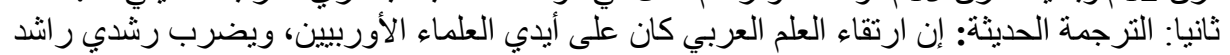

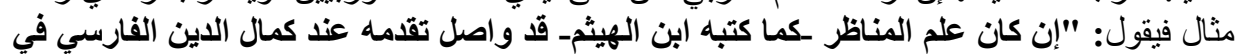

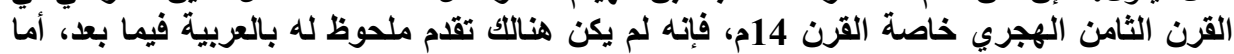

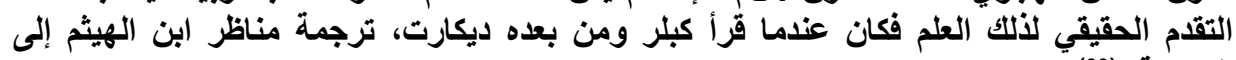

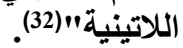
ونجد روجر بيكون 1292-1220 Roger Baconم)، قد أعطى عرضا مجملا لهندسة الإشعاع التي لإني

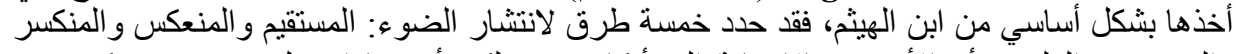

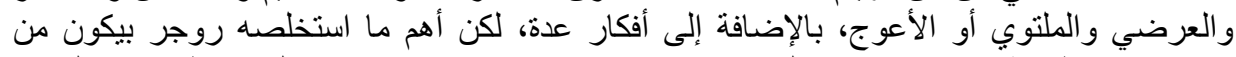

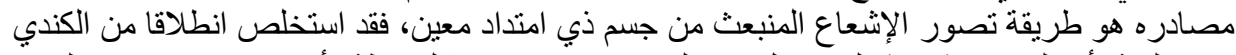

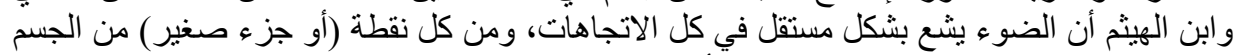

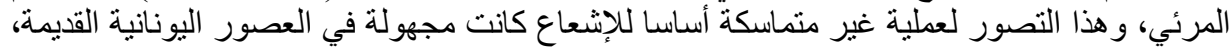

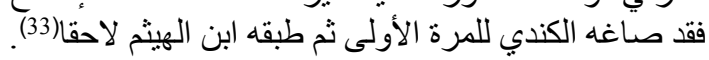

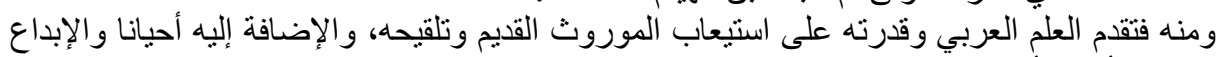

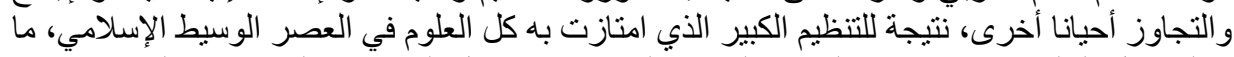

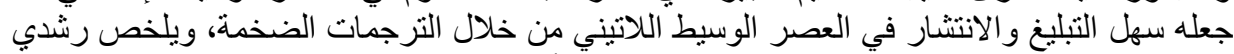

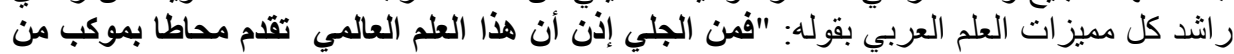

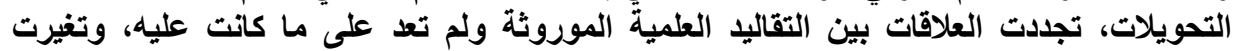

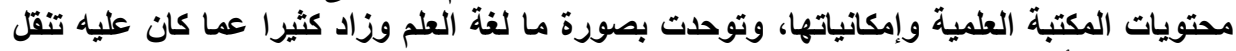

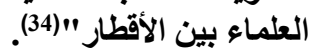
3/وحدة اللغة العلمية:

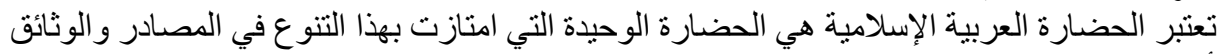

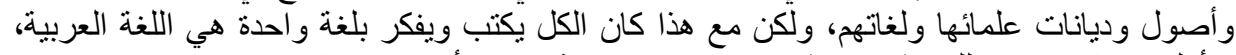

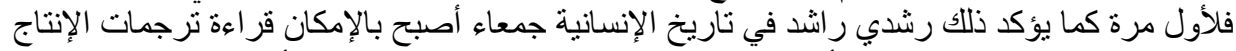

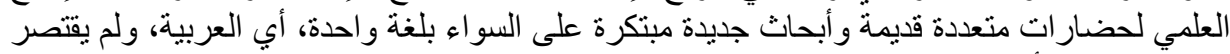

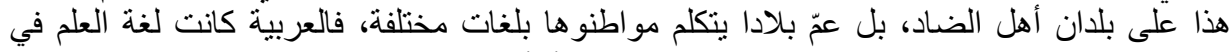

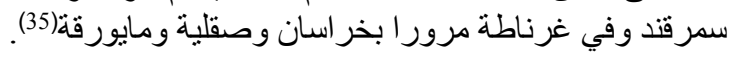


فقد كانت اللغة العربية لغة علمية، امتازت بالقدرة على التركيز والتجريد وقدرنها على توليد الألفاظ

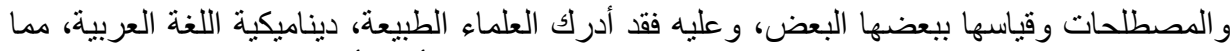

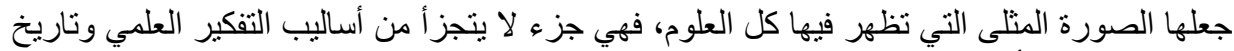

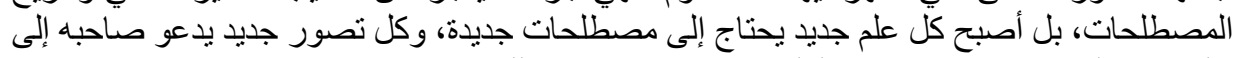

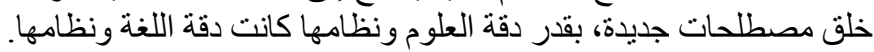

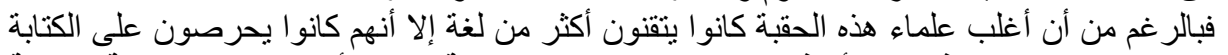

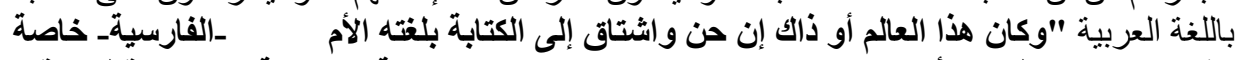

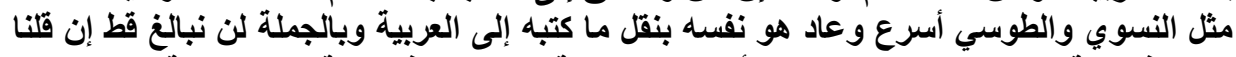

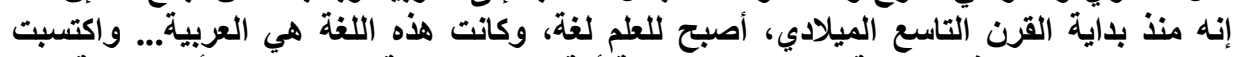

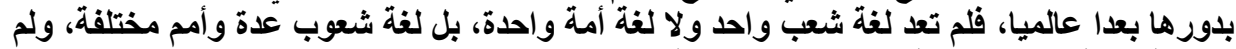

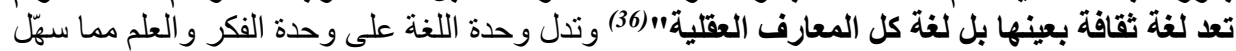

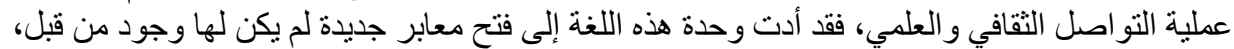

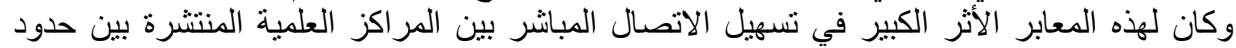
الصبن وبين الأندلس (37).

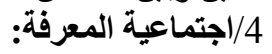

ظهر العلم العربي ومنذ البداية في أحضان المجتمع العربي الإسلامي، وتطوره في مستويين بحسب

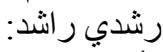
أ أمستوى المدينة الإسلامية:

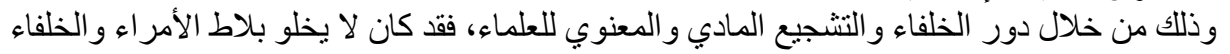

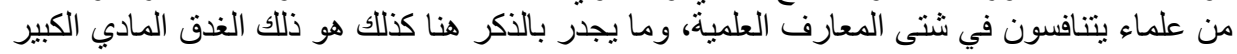

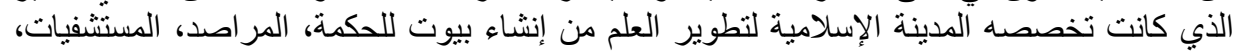

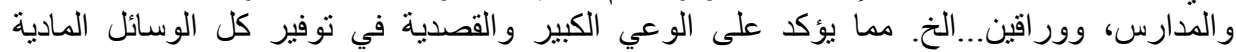

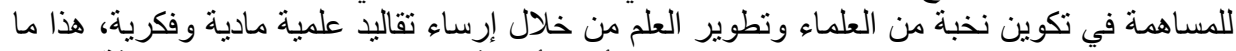

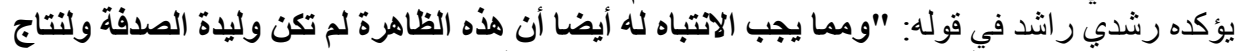

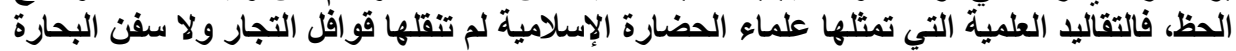

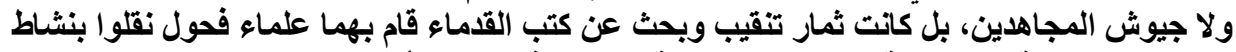

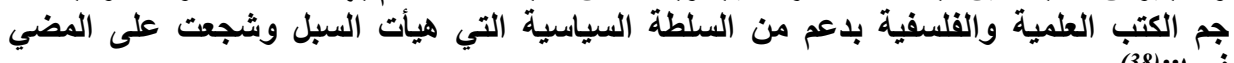

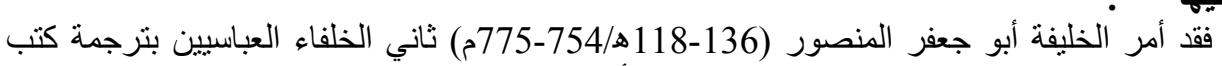

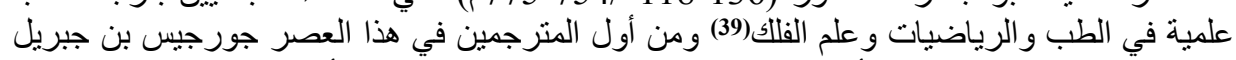

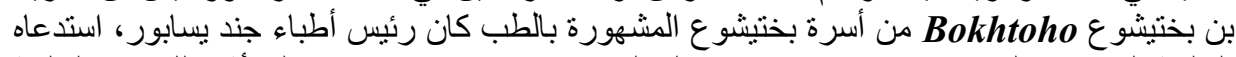

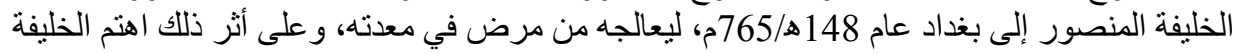

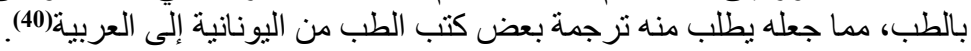

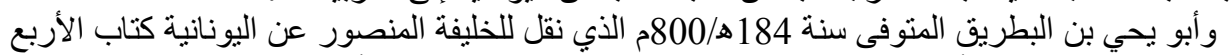

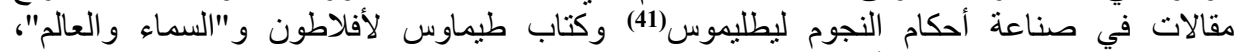
"الحيوان"، "الآثار العلوية" لأرسطو (42).

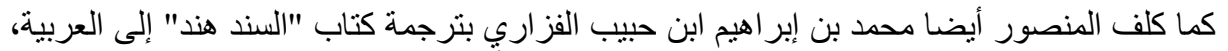

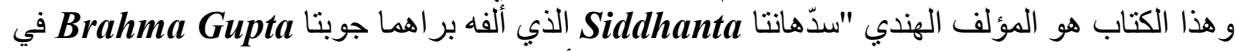

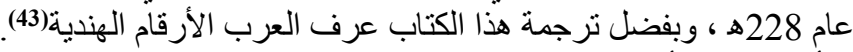

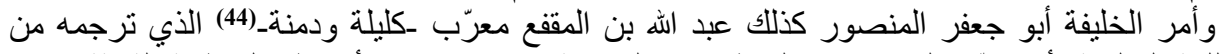

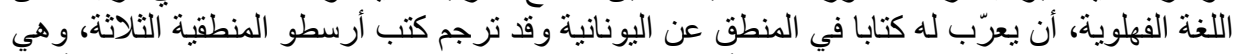

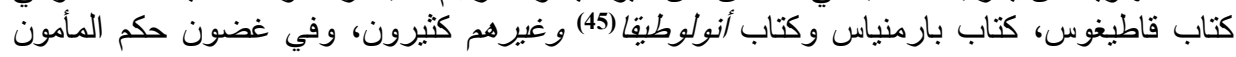


(833-813/218-198ه)، وصلت جهود رعاية الخلفاء للعلماء و العلم لأقصى المستويات، فقد كان

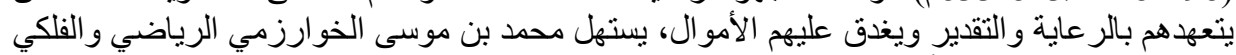

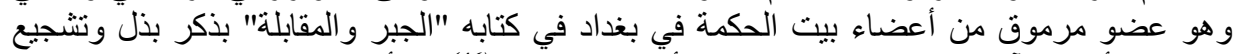

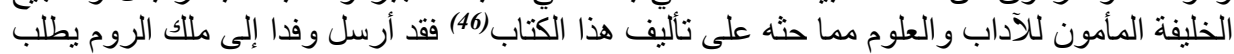

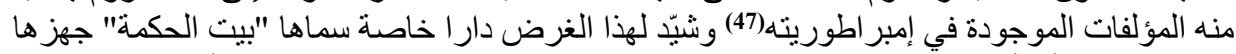

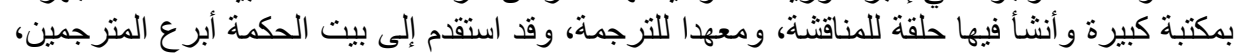

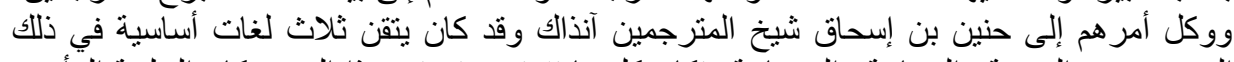

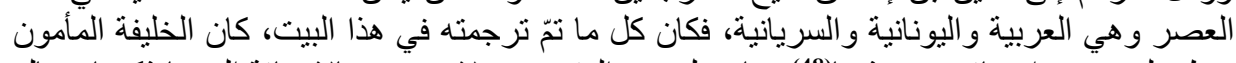

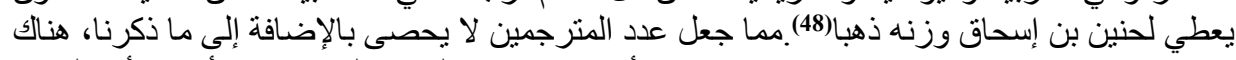

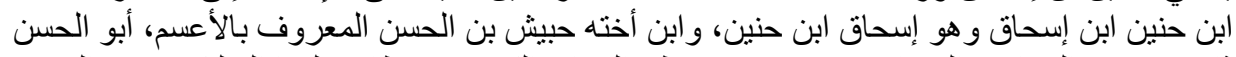

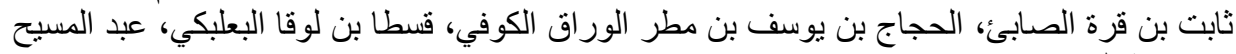

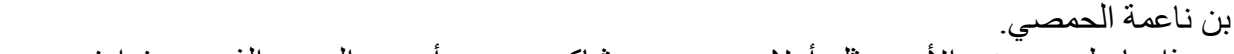

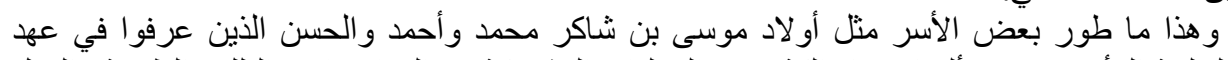

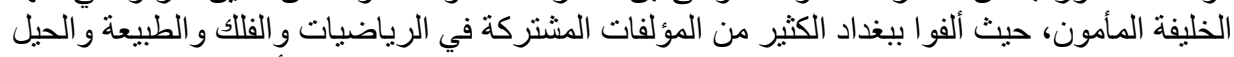

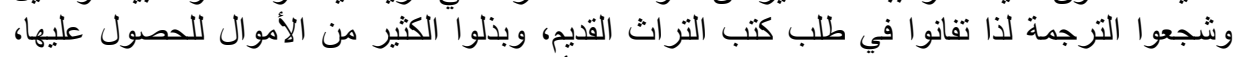

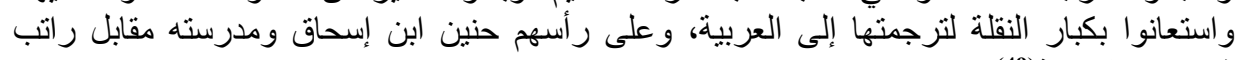

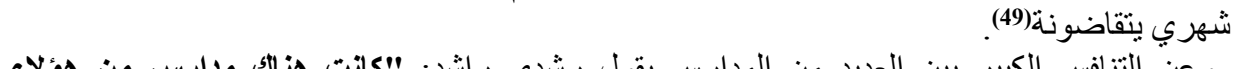

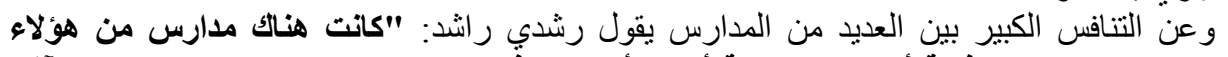

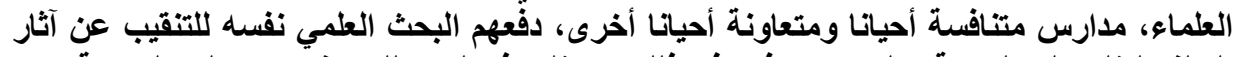

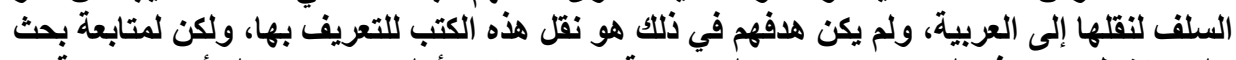

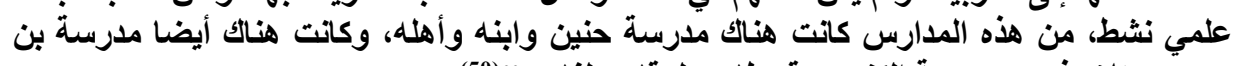

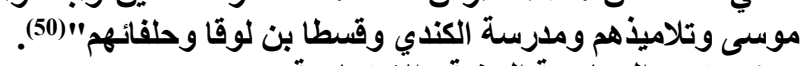
بان/مستوى الممارسة الاينية والاجتماعية:

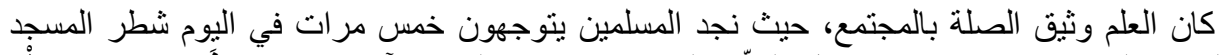

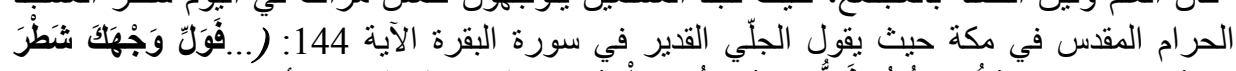

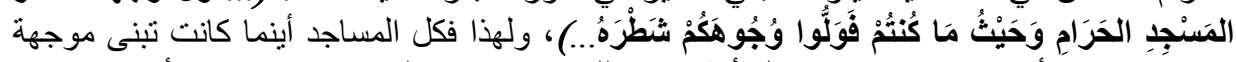

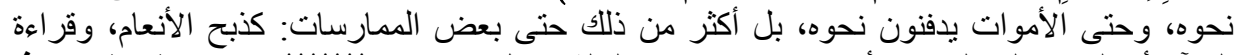

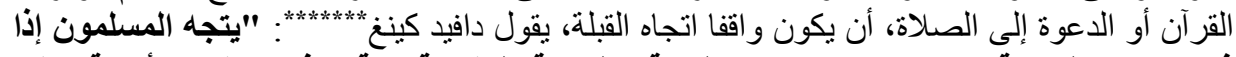

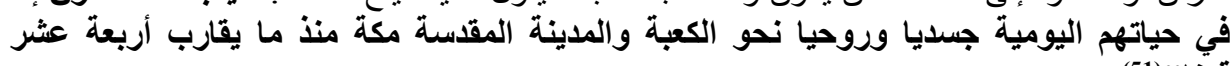

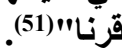

ولهذه الأهمية الدينية والدنيوية للكعبة، عكف فلكيو تلك الحقبة على تعيين وتحديد القبلة حسابيا، انطلاقا

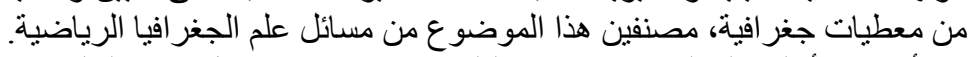

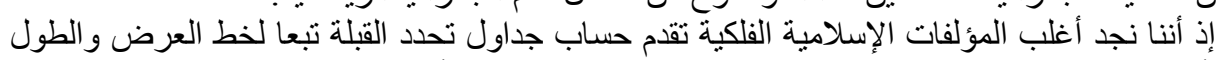

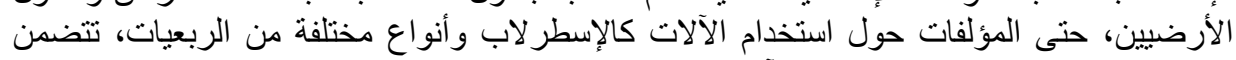

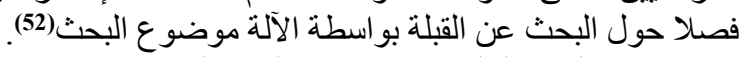

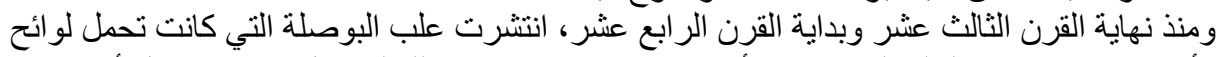

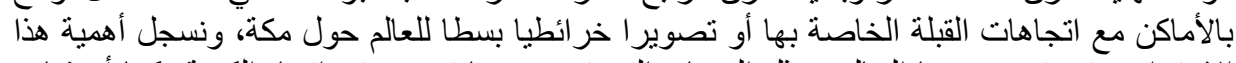

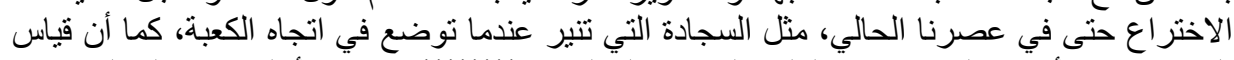

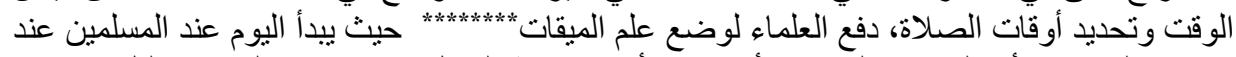

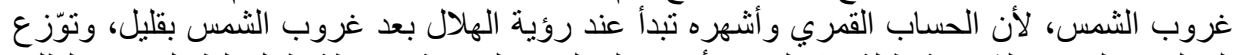

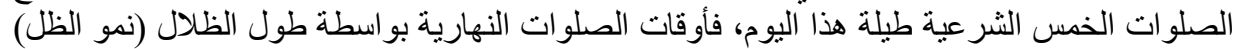
أما أوقات الصلوات الليلية تحدد بواسطة ظو اهر تحدث في الأفق وبو اسطة الغسق والية السحر ، كما أنا هناك الك 
صلاة سادسة، معتمدة عند بعض الجماعات، اسمها الضحى وتقع في منتصف الصبيحة(53) ويعتبر

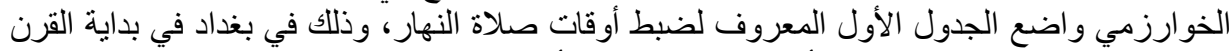

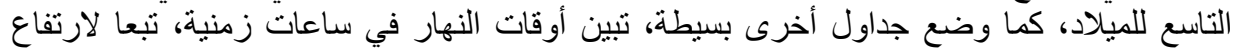

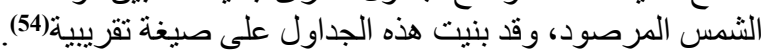

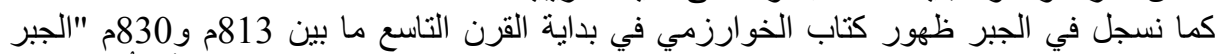

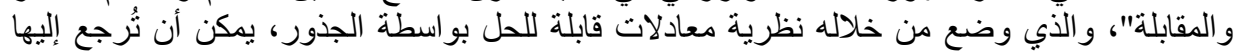

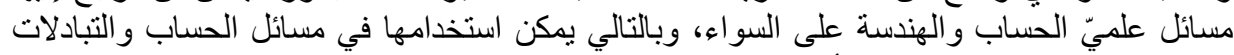

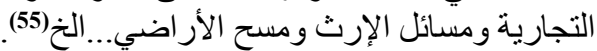

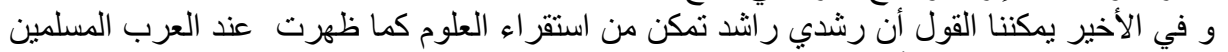

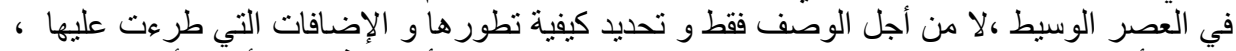

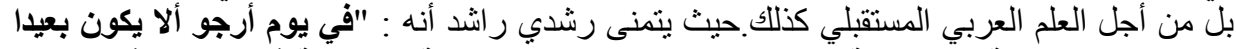

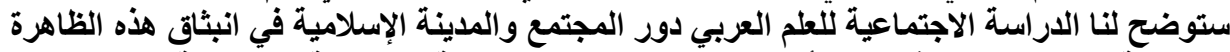

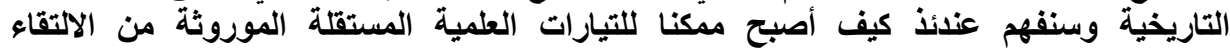

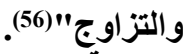
الخاتمـة

و الخلاصة أن رشدي ر اثثد رسم الخطوط العريضة التي تمكّن من التعرّف على معالم الأصالة في العلم

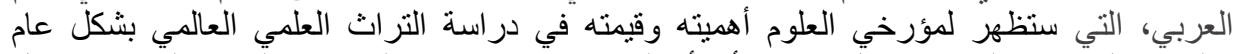

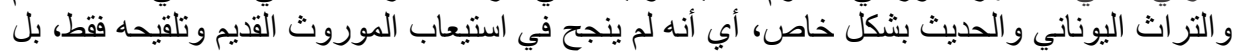

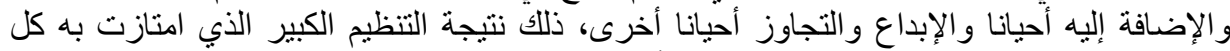

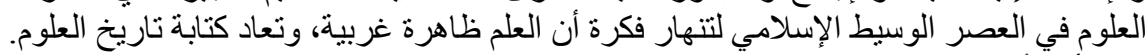

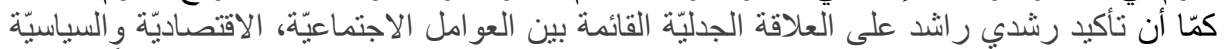

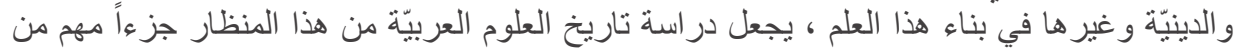
در اسة تاريخ الحضارة الإسلامية.

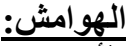

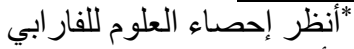

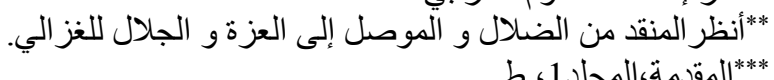

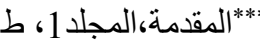

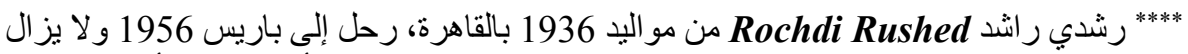

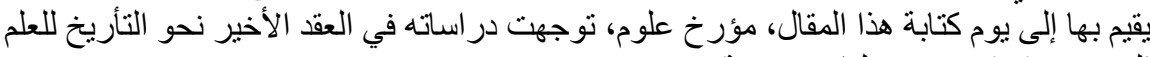

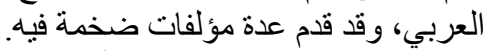
1- رشندي راثد: العلوم العربية بين نظرية المعرفة والتاريخ، مجلة الفلسفة و العصر، المجلس الأعلى

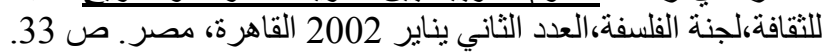

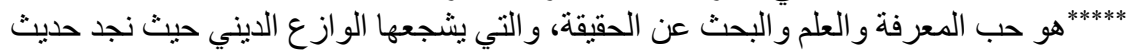

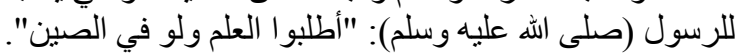

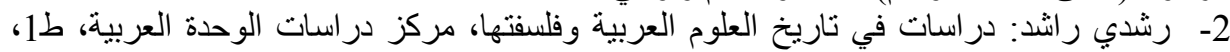

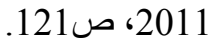

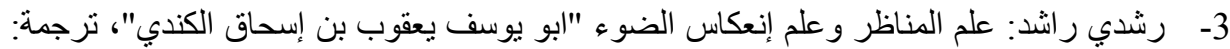

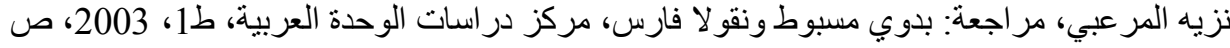
5- كلود برنار : مدخل لدراسة الطب التجريبي، ترجمة: عمر الشارني، دار بوسلامة للطباعة و النشر

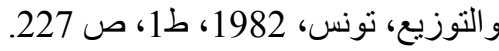


أحقيق ما للهند من مقولة مقولة في الاعقل أم مرذولة، مطبعة دائرة المعارف

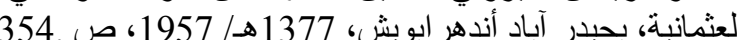
7- أبو الريحان البيروني: الباد أندانون المسعودي، اهني، مطبعة جمعية مجلس دائرة المعارف العثمانية، بحيدر

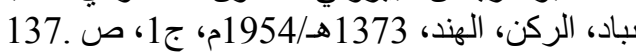

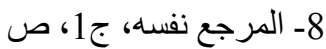

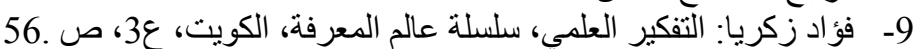

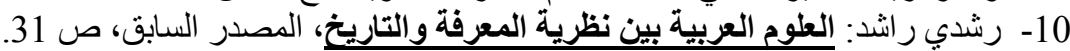

11-R.R : Yoush kevitch, Historien des mathématiques arabes, archives

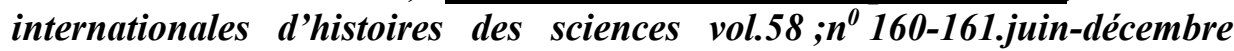
2008.p11

12- أبو ريحان البيروني: تحقيق ما للهند من مقولة مقبولة في العقل أو مرذولة،مطبعة دار المعارف

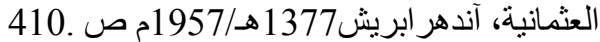

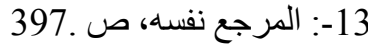

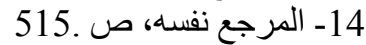

15- نقلا عن أحمد زكي يماني: الرياضيات التحليلية لرشدي راشد،نصوص فئس و دراسات من التراث

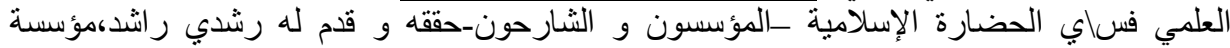

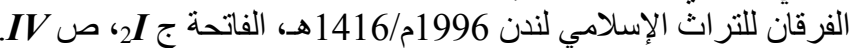

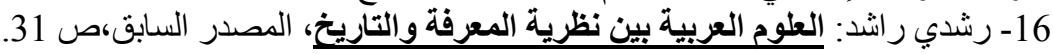

17- R.R : Yoush kevitch,: Op.cit,p 11.

18- رشدي راشد: تاريخ العلم والعطاء العلمى في الوطن العربي، مجلة المستقبل العربي ، السنة

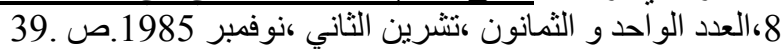

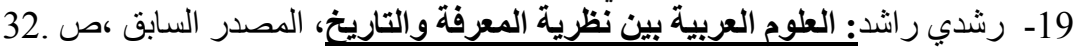

20

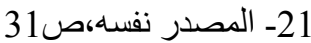

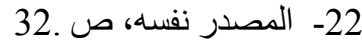

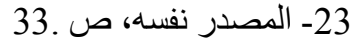

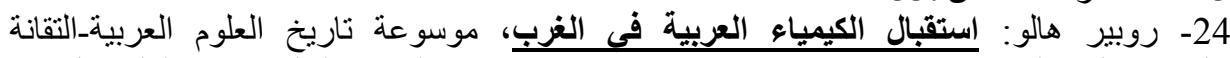

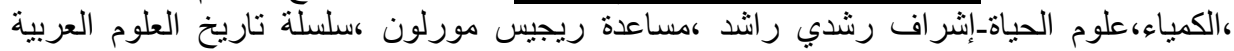

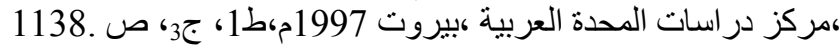

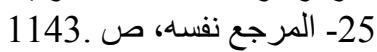

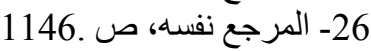

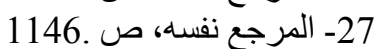

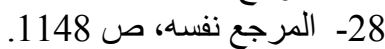

(*) الأسطر لاب: آلة تعليمية بامتياز في القرون الوسطى، وهو أيضا آلة حسابية، إذ أنه سمح بحل

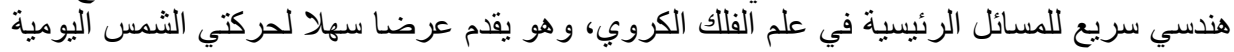

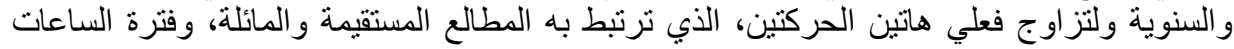

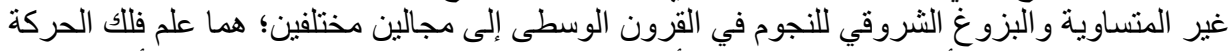

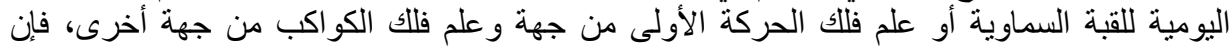
المؤلفات عن الأسطر لاب ترنبط بالمجال الأول. 
29- هنري هو غونار -روش: تأثثير علم الفلك العربى في الغرب في القرون الوسطي، موسوعة تاريخ

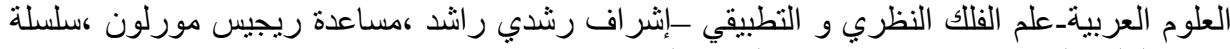

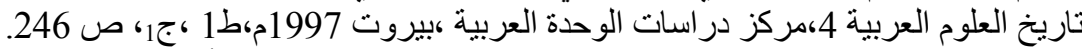

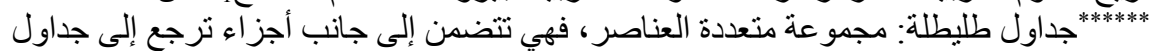

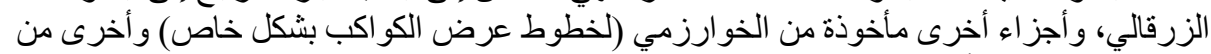

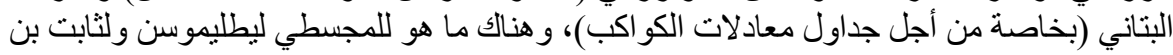

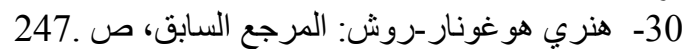

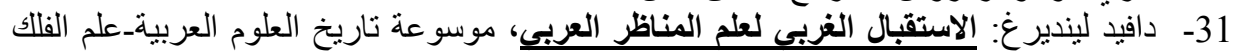

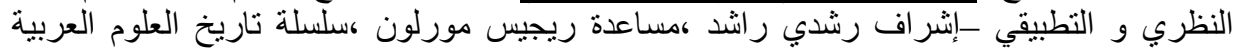

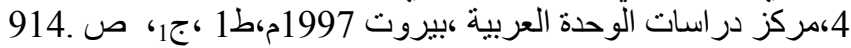

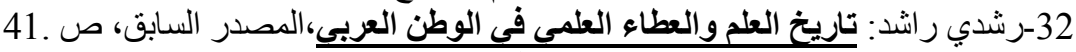

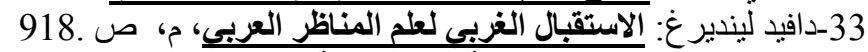

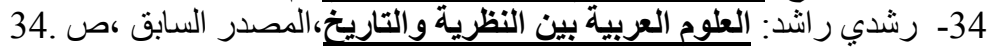

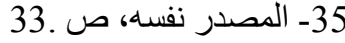

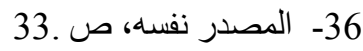

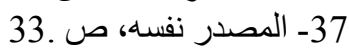

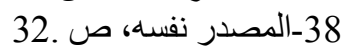

39- دومنيك أورفوا: تاريخ الفكر العربى الإسلامى، ترجمة رندة بعث، المكتبة الثرقية، طه، 2010م،

181. صن

40-سير توماس أرنولد وآخرون: تراث الإسلام، ترجمة جرجيس فتح الله، ط3، دار الطليعة، بيروت،

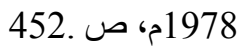

41-كمال اليازجي: معالم الفكر العربى فى العصر الوسيط، دار العالم للملايين، مصر، طه، 1966،

64. ص

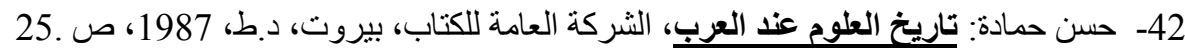

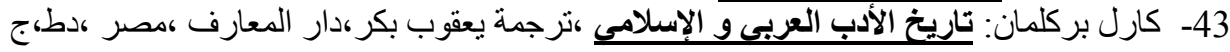

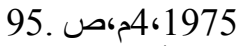

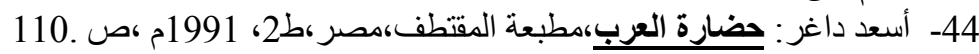

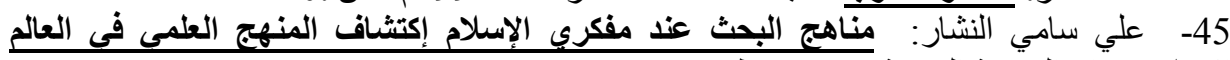

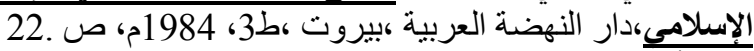

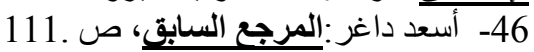

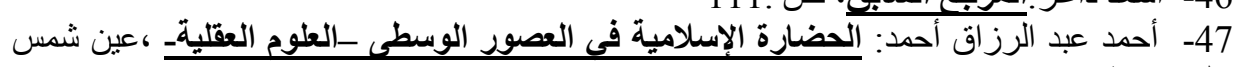

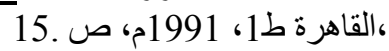

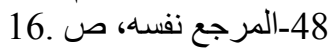

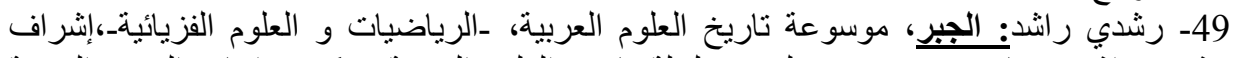

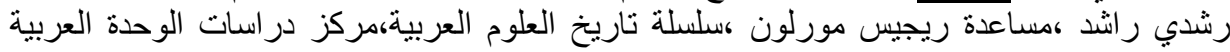

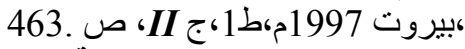

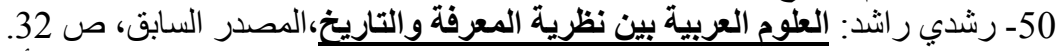

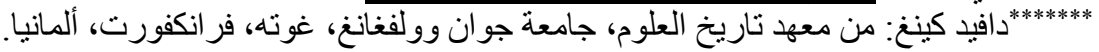

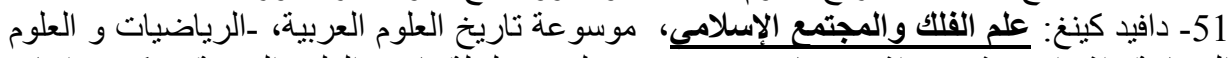

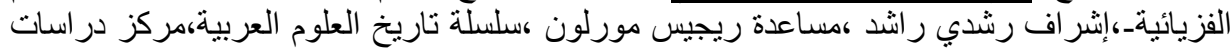

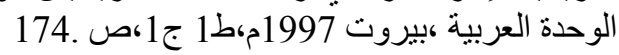


52- المرجع نفساه، ص 197.

53

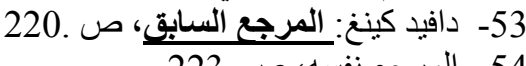

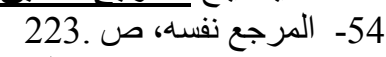

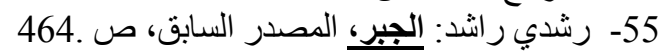

56- رشدي ر اثند: العلوم العربية بين نظرية المعرفة والتاريخ، المصدر السابق، ص 32. 